Jurnal Intelektualita: Keislaman, Sosial, dan Sains

Vol. 9 No. 2 (2020)

DOI: https://doi.org/10.19109/intelektualita.v9i2.6793

Copyright (C) 2020 Anita Aprilia Rachman, Astuti Darmiyati, Dewi Siti Aisyah

\title{
Pengaruh Penggunaan Model Pembelajaran Make A Match terhadap Keaktifan Belajar Siswa di SMPN 1 Kotabaru Karawang
}

\author{
Anita Aprilia Rachman ${ }^{1 *}$, Astuti Darmiyati ${ }^{1}$, Dewi Siti Aisyah ${ }^{1}$ \\ ${ }^{1}$ Universitas Singaperbangsa Karawang, Indonesia
}

\begin{abstract}
Abstrak: Penelitian ini bertujuan untuk mengetahui pengaruh model pembelajaran make a match terhadap keaktifan belajar siswa di SMPN 1 Kotabaru Karawang. Penelitian ini menggunakan pendekatan kuantitatif dengan jenis penelitian survei kelembagaan sekolah. Populasi penelitian sebanyak 200 siswa dengan menggunakan teknik sampling purposive kelas VII H. Jenis data yang digunakan yaitu data nominal, data interval, dan data rasio. Sedangkan instrumen yang digunakan pada penelitian ini adalah kuesioner, wawancara, test dan dokumentasi. Teknik analisis data nya menggunakan distribusi frekuensi, uji normalitas, uji autokorelasi, uji korelasi, uji determinasi, dan uji regresi linearitas sederhana. Hasil yang dianalisis sebagai berikut: 1). Penggunaan model pembelajaran make a match, 2). Keaktifan belajar siswa kelas VII, 3). Adanya pengaruh model pembelajaran make a match terhadap keaktifan belajar siswa yang signifikan kelas VII di SMPN 1 Kotabaru Karawang.
\end{abstract}

Kata Kunci: keaktifan belajar, model pembelajaran make a match

\begin{abstract}
This study aims to determine the effect of the make a match learning model on student learning activeness at SMPN 1 Kotabaru Karawang. This study uses a quantitative approach with the type of school institutional survey research. The study population was 200 students using purposive sampling technique class VII $\mathrm{H}$. Types of data used were nominal data, interval data, and ratio data. While the instruments used in this study were questionnaires, interviews, tests and documentation. The data analysis technique uses frequency distribution, normality test, autocorrelation test, correlation test, determination test, and simple linearity regression test. The results analyzed are as follows: 1). The use of the make a match learning model, 2). Class VII student learning activeness, 3). The influence of the make a match learning model on student learning activeness is significant for grade VII at SMPN 1 Kotabaru Karawang.
\end{abstract}

Keywords: activity learning, make a match learning model

\section{Pendahuluan}

Menurut UU RI Nomor 20 Tahun 2003 Tentang Sistem Pendidikan Nasional, "Pendidikan adalah usaha sadar untuk mewujudkan proses pembelajaran agar peserta didik aktif dan mengembangkan potensi diri, spiritual, pengendalian diri, akhlak mulia yang diperlukan dirinya bagi bangsa dan negara.

Konsep pembelajaran aktif bukanlah tujuan dari kegiatan pembelajaran, tetapi merupakan salah satu usaha guru untuk menciptakan siswa agar tidak bosan dalam pembelajaran. Pembelajaran aktif itu

\footnotetext{
* Corresponding Author: Aniti Aprilia Rachman (apriliaanita117@gmail.com). Universitas Singaperbangsa Karawang, Indonesia
} 
siswa yang aktif disaat proses belajar, aktif dalam mengemukakan pendapat, berdiskusi dan bertanya jika tidak dimengerti. Model pembelajaran merupakan pondasi awal untuk mencapai suatu tujuan pendidikan dan keberhasilan dalam pembelajaran. Sebagaimana firman Allah SWT dalam Q.S. An-Nahl ayat 125 yang berbunyi:

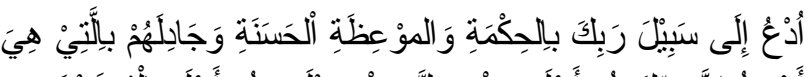

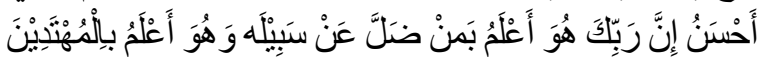

Artinya: "Serulah (manusia) kepada jalan Tuhanmu dengan hikmah dan pelajaran yang baik dan bantahlah mereka dengan cara yang baik. Sesungguhnya Tuhanmu Dialah yang lebih mengetahui tentang siapa yang tersesat dari jalanNya dan Dialah yang lebih mengetahui orang-orang yang mendapat petunjuk". (Q.S. An-Nahl: 125).

Keberhasilan dalam kegiatan pembelajaran bisa dilihat dari tingginya keaktifan siswa dalam kegiatan pembelajaran. Berdasarkan pengamatan yang telah dilakukakan, keaktifan siswa dalam pembelajaran sangat rendah. Ketika siswa diminta oleh guru untuk bertanya mengenai materi yang sedang dipelajari, tidak ada siswa yang mengangkat tangan dan bertanya. Model pembelajaran make a match ini pembelajaran memasangkan 2 kartu, yaitu kartu jawaban dan kartu pertanyaan. Sehingga materi ini sangat cocok untuk diaplikasikan dengan permainan berpasangan kartu.

\section{Metode Penelitian}

Penelitian ini menggunakan pendekatan kuantitatif jenis penelitian survei kelembagaan sekolah. Kuantitatif adalah pendekatan dalam penelitian ini sebagai penekatan penelitian yang berdasarkan pada filsafat positivisme, digunakan untuk meneliti pada populasi atau sampel tertentu, teknik pengumpulan data menggunakan kuesioner angket, wawancara, test dan dokumentasi, analisis data bersifat kuantitatif/perhitungan angka-angka, dengan tujuan untuk mengukur adanya pengaruh penggunaan model pembelajaran make a match meningkatkan keaktifan belajar siswa kelas VII. Penelitian ini dengan populasi sebanyak 200 siswa, dengan sampelnya menggunakan teknik sampling purposive sebesar 37 di kelas VII $\mathrm{H}$ karena mempunyai keaktifan belajar yang kurang dengan kelas lain. Penelitian ini menggunakan teknik analisis data yaitu distribusi frekuensi, uji normalitas, uji autokorelasi, uji korelasi, dan uji regresi linearitas sederhana untuk mengetahui adanya pengaruh model pembelajaran make a match terhadap keaktifan belajar siswa yang signifikan.

\section{Hasil Penelitian dan Pembahasan}

\section{Analisis Data}

Tabel 1. Hasil analisis model pembelajaran make a match

\begin{tabular}{|c|c|c|c|c|c|c|}
\hline & $\mathrm{N}$ & Range & Minimum & Maximum & Mean & Std \\
\hline Model & & 12 & 20 & 32 & 24.97 & 3.29 \\
$\begin{array}{c}\text { Pembelajaran } \\
\text { Make A Match }\end{array}$ & 37 & & & & & \\
Valid Missing & 37 & & & & & \\
\hline
\end{tabular}

Hasil analisis data di atas dengan penyebaran kuesioner variabel X model pembelajaran make a match dengan item soal sebanyak 10 menghasilkan nilai mean sebesar 24,97 dengan nilai maksimal sebesar 32 . 
Tabel 2. Kategorisasi skor model pembelajaran make a match

\begin{tabular}{|c|rr|c|c|}
\hline No & \multicolumn{2}{|c|}{ Rentang Skor (i) } & Nilai & Kategori \\
\hline 1 & Valid & $29.90-30.00$ & A & Sangat Baik \\
\hline 2 & $24.97-29.90$ & B & Baik \\
\hline 3 & $20.03-24.97$ & C & Cukup \\
\hline 4 & $20.00-20.03$ & D & Kurang Baik \\
\hline
\end{tabular}

Hasil dari tabel tersebut, menghasilkan data kategori pertama sebesar 29.90 - 30.00 A (Sangat baik), kategori kedua sebesar 24.97 - 29.90 B (Baik), ketegori ketiga sebesar $20.03-24.97 \mathrm{C}$ (Cukup), kategori keempat sebesar 20.00 - 20.03 D (kurang baik). Dari rata-rata (mean) variabel model pembelajaran make a match merupakan kategori baik (B).

Tabel 3. Hasil analisis keaktifan belajar siswa

\begin{tabular}{|c|c|c|c|c|c|c|}
\hline & N & Range & Minimum & Maximum & Mean & Std \\
\hline $\begin{array}{c}\text { Keaktifan Belajar } \\
\text { Siswa }\end{array}$ & 37 & 17 & 22 & 39 & $\mathbf{3 0 . 9 5}$ & $\mathbf{4 . 6 0}$ \\
Valid Missing & 37 & & & & & \\
\hline
\end{tabular}

Hasil analisis data di atas dengan penyebaran kuesioner variabel $\mathrm{Y}$ keaktifan belajar siswa dengan item soal sebanyak 10 menghasilkan nilai mean sebesar 30,95 dengan nilai nilai maksimal sebesar 39.

Tabel 4. Kategori skor keaktifan belajar siswa

\begin{tabular}{|c|r|c|c|}
\hline No & \multicolumn{1}{|c|}{ Rentan Skor (i) } & Nilai & Kategori \\
\hline 1 & Valid $37.85-38.00$ & A & Sangat Baik \\
\hline 2 & $30.95-37.85$ & B & Baik \\
\hline 3 & $24.05-30.95$ & C & Cukup \\
\hline 4 & $24.00-24.05$ & D & Kurang Baik \\
\hline
\end{tabular}

Hasil dari tabel tersebut, menghasilkan data kategori pertama sebesar 37.85 - 38.00 A (Sangat baik), kategori kedua sebesar 30.95 - 37.85 B (Baik), ketegori ketiga sebesar 24.05 - 30.95 C
(Cukup), kategori keempat sebesar 24.00-24.05 D (kurang baik). Dari rata-rata (mean) variabel model pembelajaran make a match merupakan kategori baik (B).

Tabel 5. Uji normalitas

One-Sample Kolmogorov-Smirnov Test

\begin{tabular}{|ll|c|}
\hline & & $\begin{array}{c}\text { Unstandardized } \\
\text { Residual }\end{array}$ \\
\hline Normal Parameters ${ }^{\mathrm{a}}$ & Mean & 37 \\
& Std. Deviation & .0000000 \\
Most Extreme Differences & Absolute & 4.22984344 \\
& Positive & .089 \\
& Negative & .073 \\
Kolmogorov-Smirnov Z & & -.089 \\
Asymp. Sig. (2-tailed) & & $\mathbf{5 4 3}$ \\
& & $\mathbf{. 9 2 9}$ \\
\hline a. Test distribution is Normal. & & \\
\end{tabular}

Berdasarkan tabel di atas menghasilkan data kolmogrov smirnov sebesar 0.543 dengan sig (2tailed) sebesar 0.929 bahwa model pembelajaran make a match terhadap keaktifan belajar bersifat normal.

Tabel 6. Uji autokorelasi

Model Summary ${ }^{b}$

\begin{tabular}{|c|c|c|c|c|c|}
\hline $\begin{array}{c}\text { Mod } \\
\text { el }\end{array}$ & $\mathrm{R}$ & $\begin{array}{c}\mathrm{R} \\
\text { Square }\end{array}$ & $\begin{array}{c}\text { Adjusted R } \\
\text { Square }\end{array}$ & $\begin{array}{c}\text { Std. Error } \\
\text { of the } \\
\text { Estimate }\end{array}$ & $\begin{array}{c}\text { Durbin- } \\
\text { Watson }\end{array}$ \\
\hline 1 & $.393^{\mathrm{a}}$ & .155 & .130 & 4.290 & $\mathbf{2 . 0 5 1}$ \\
\hline
\end{tabular}

a. Predictors: (Constant), X(make a match)

Berdasarkan hasil tabel uji autokorelasi didapatkan diketahui untuk nilai $\mathrm{DW}=\mathbf{2 . 0 5 1}$, dibandingkan dengan nilai tabel signifikansi $5 \%$ $(0,05)$ dengan jumlah sampel 37 dan jumlah independent $1(\mathrm{~K}=1)=1,37$ sehingga didapatkan hasil dU dari tabel tabel $r=1.529$. nilai DW lebih besar dari nilai dU dan kurang dari (4-dU) $=4-$ 
$1.529=$ 2.471 sehingga disimpulkan bahwa tidak terdapat autokorelasi.

Tabel 7. Uji Korelasi

\section{Correlations}

\begin{tabular}{|cc|c|c|}
\hline & & $\mathrm{X}$ & $\mathrm{Y}$ \\
\hline $\mathrm{X}$ & Pearson Correlation & 1 & $\mathbf{- . 3 9 3}^{*}$ \\
& Sig. (2-tailed) & & $\mathbf{. 0 1 6}$ \\
$\mathrm{N}$ & 37 & 37 \\
\hline $\mathrm{Y}$ & Pearson Correlation & $\mathbf{- . 3 9 3}^{*}$ & 1 \\
& Sig. (2-tailed) & $\mathbf{. 0 1 6}$ & \\
$\mathrm{N}$ & 37 & 37 \\
\hline
\end{tabular}

*. Correlation is significant at the 0.05 level (2-tailed).

Disimpulkan dari hasil tabel korelasi dengan menggunakan SPSS Versi 16.0 nilai sig (2-tailed) yaitu 0,16 antara variabel $\mathrm{X}$ dengan $\mathrm{Y}$ sama berarti memiliki hubungan antara variabel $X$ terhadap variabel $\mathrm{Y}$ tetapi lemah, jenis pearson correlation variable $\mathrm{X}$ (make a match) dengan variabel $\mathrm{Y}$ (keaktifan belajar) bersifat negatif dan memiliki angka sama yaitu (393).

Tabel 8. Koefisien determinasi

Model Summary

\begin{tabular}{|c|c|c|c|c|}
\hline Model & $\mathrm{R}$ & R Square & $\begin{array}{c}\text { Adjusted R } \\
\text { Square }\end{array}$ & $\begin{array}{c}\text { Std. Error of } \\
\text { the Estimate }\end{array}$ \\
\hline 1 & $.962^{\mathrm{a}}$ & $\mathbf{. 9 2 6}$ & $\mathbf{. 9 2 4}$ & 1.266 \\
\hline
\end{tabular}

a. Predictors: (Constant), Make_a_match

Berdasarkan tabel di atas, diperoleh nilai determinasi ( $R$ Square) sebesar 0.926, yang dapat dimaknai bahwa variabel model pembelajaran make a match ini memberikan pengaruh $92.4 \%$ terhadap keaktifan belajar siswa sisanya sebesar $7.6 \%$ berasal dari faktor lain.
Tabel 6. Uji regresi linearitas

\begin{tabular}{|c|c|c|c|c|c|}
\hline \multicolumn{6}{|c|}{ Coefficients $^{\mathrm{a}}$} \\
\hline \multirow[b]{2}{*}{ Model } & \multicolumn{2}{|c|}{$\begin{array}{l}\text { Unstandardized } \\
\text { Coefficients }\end{array}$} & $\begin{array}{c}\text { Standardi } \\
\text { zed } \\
\text { Coefficie } \\
\text { nts }\end{array}$ & \multirow[b]{2}{*}{$\mathrm{t}$} & \multirow[b]{2}{*}{ Sig. } \\
\hline & B & $\begin{array}{l}\text { Std. } \\
\text { Error }\end{array}$ & Beta & & \\
\hline 1 (Constant) & -2.693 & 1.617 & & -1.665 & .105 \\
\hline $\begin{array}{l}\text { Make_a_ } \\
\text { match }\end{array}$ & 1.347 & .064 & .962 & $\begin{array}{r}20.97 \\
7\end{array}$ & .000 \\
\hline
\end{tabular}

Cara mencari $t_{\text {tabel }}$ dengan rumus:

$$
\begin{aligned}
t_{\text {tabel }} & =\frac{\alpha}{2}: \mathrm{n}-\mathrm{k}-1 \\
& =\frac{0,05}{2}: 37-1-1 \\
& =0.025: 35 \text { (dilihat pada distribusi }
\end{aligned}
$$

nilai $\left.t_{\text {tabel }}\right)$

$$
=2.030
$$

Berdasarkan nilai $\mathrm{t}$ : diketahui nilai $t_{\text {hitung }}$ sebesar $20.977>t_{\text {tabel }} \mathbf{2 . 0 3 0}$, sehingga dapat disimpulkan bahwa variabel model pembelajaran make a match $(\mathrm{X})$ berpengaruh terhadap variabel keaktifan belajar siswa (Y).

\section{Kesimpulan}

Berdasarkan hasil analisis dan pembahasan data melalui uji normalitas, uji autokorelasi, uji korelasi, uji determinasi dan uji regresi linear sederhana dengan menggunaka SPSS 16.0 yaitu pertama, penggunaan model pembelajaran make a match kelas VII H di SMPN 1 Kotabaru berada dalam kategori baik. Hal itu ditunjukkan dengan rata-rata (mean) sebesar 24.97, range sebesar 12 standar deviasi sebesar 3.29 dengan panjang kelas intervalnya sebesar 2; kedua, hasil dari keaktifan belajar siswa Pendidikan Agama Islam menghasilkan dalam kategori baik dengan rata-rata (mean) sebesar 30.95, standar deviasi sebesar 4.60 
dan nilai range sebesar 17 dengan panjang kelas interval sebesar; dan ketiga, pengaruh model pembelajaran make a match terhadap keaktifan belajar siswa Pendidikan Agama Islam di SMPN 1 Kotabaru menghasilkan adanya korelasi antara variabel $\mathrm{X}$ terhadap variabel $\mathrm{Y}$, berdasarkan $r($ pearson $)>r($ tabel $)$ sehingga $(0,393)>(0,325)$ maka dapat disimpulkan bahwa ada hubungan atau korelasi tetapi lemah antara variabel $\mathrm{X}$ terhadap variabel Y. Sedangkan nilai sig (2-tailed) < nilai sig menghasilkan $(0,016)<(0,05)$ maka ada hubungan yang signifikan, dan nilai $t_{\text {hitung }}$ sebesar $20.977>$ $t_{\text {tabel }} 2.030$ maka ada pengaruh model pembelajaran make a match terhadap keaktifan belajar siswa yang signifikan.

\section{Daftar Pustaka}

Dwi Cahyani, P. Pengaruh Model pembelajaran Make A Match terhadap belajar di SMK Nasional Bandung: 2017.

Fathurrohman, M. Model-Model Pembelajaran Inovatif. Yogyakarta: Ar-Ruzz Media. 2015

Istarani. 58 Model Pembelajaran Inovatif. Medan: Media Persada. 2015.

Jamaris, M. Orientasi Baru dalam Psikologi Pendidikan . Bogor: Ghalia Indonesia. 2013.

Kurniasih, I., \& Sani, B. Ragam Pengembangan Model Pembelajaran. Kata Pena. 2016.

Poerwardarminta. 1984. Kamus Besar Bahasa Indonesia. Jakarta: Balai Pustaka. 1984.

Padjrin, P. (2016). Pola Asuh Anak dalam Perspektif Pendidikan Islam. Jurnal Intelektualita: KeIslaman, Sosial Dan Sains, 5(1), $\quad 1 \quad 14$. https://doi.org/https://doi.org/10.19109/intele ktualita.v5i1.720

Zaini, H., Hadi, A., Sofyan, F. A., \& Hamzah, A. (2021). Covid-19 and Islamic Education in School: Searching for Alternative Learning Media. Webology, 18(1).

Riadi, Edi. Statistika Penelitian (Analisis Manual dan IBM SPSS). Yogyakarta: CV. Andi Offset. 2016.

Shoimin, A. (cetakan II). 68 Model Pembelajaran Inovatif dalam Kurikulum 2013. Yogyakarta. 2018.
Sinar. Metode Active Learning. Yogyakarta: CV Budi Utama. 2018.

Uno, H., \& Mohamad, N. Belajar dengan Pendekatan PAILKEM. Jakarta: PT Bumi Aksara. 2014.

Uzer Usman, M. Menjadi Guru Profesional. Bandung: PT Remaja Rosdakarya. 2017.

Warsono. Pembelajaran Aktif Teori dan Assesment. Bandung: Remaja Rosdakarya. 2012.

https://www/maxmanroe.com/vid/umum/metode pembelajaran.html. dilihat hari jum'at tanggal 8 Mei 2020. 